\title{
Forensisen lingvistiikan uudet haasteet: Raportti IAFL2017-konferenssista
}

Porton yliopistossa Portugalissa järjestettiin 10.-14. heinäkuuta 2017 International Association of Forensic Linguists -yhdistyksen ${ }^{1}$ (IAFL) järjestyksessään 13. forensisen lingvistiikan alan konferenssi. ${ }^{2}$ IAFL on Isossa-Britanniassa vuonna 1992 perustettu forensisen lingvistiikan alan toimijoiden yhdistys, jonka ensisijaisena tavoitteena on edistää oikeusjärjestelmien toimintaa ja oikeuden toteutumista maailmanlaajuisesti lisäämällä yleistä tietoisuutta oikeuden ja kielen välisestä suhteesta sekä tuottaa tieteellistä tietoa erilaisista kielellisistä haasteista ja näiden ratkaisemisesta oikeudellisissa prosesseissa. Yhdistys järjestää joka toinen vuosi forensisen lingvistiikan konferenssin, jossa esitellään alan uusia kehityssuuntauksia. Lisäksi yhdistyksen jäsenet ovat vuodesta 1994 lähtien toimittaneet alan merkittävimpiin lukeutuvaa vertaisarvioitua lehteä The International Journal of Speech, Language and the Law sekä vuodesta 2014 lähtien uutta kaksikielistä vertaisarvioitua verkkolehteä Language and Law/ Linguagem e Direito. Ennen kuin kerron tarkemmin viimeisimmästä konferenssista, taustoitan hieman sitä, miten forensinen lingvistiikka on saanut alkunsa.

\section{Forensinen lingvistiikka}

Forensisen lingvistiikan tieteenalan katsotaan juontavan juurensa vuoteen 1968 ,

1. http://www.iafl.org/.

2. https://iaflporto2017.com/. jolloin Lundin yliopiston englannin kielen professori Jan Svartvik julkaisi ensimmäisen tapaustutkimuksen kielellisistä todisteista rikosasian tutkinnassa. Tutkimuksessaan The Evans statements: A case for forensic linguistics Svartvik käsitteli vuonna 1949 Lontoossa tapahtunutta kaksoismurhaa, jonka ratkaisemisessa kielellisellä todistusaineistolla oli ollut olennainen merkitys. Tapauksessa rikoksesta epäilty, tekohetkellä 25-vuotias Timothy Evans, tuomittiin syylliseksi vaimonsa ja pienen tyttärensä kaksoismurhaan, ja hänet teloitettiin vuonna 1950.

Evansin rikosoikeudenkäynnissä annettu tuomio perustui neljään lausuntoon, jotka syytetty oli antanut Notting Hillin poliisilaitoksen viranomaisille. Näitä lausuntoja jälkikäteen analysoidessaan Svartvik havaitsi teksteissä tiettyjä kvantitatiivisin ja kvalitatiivisin tutkimusmenetelmin todistettavissa olevia tyylillisiä eroavaisuuksia ja ristiriitoja, jotka antoivat aihetta epäillä, ettei Evans olisi itse sanonut tiettyjä lausuntoihin sisältyviä, raskauttaviksi arvioituja ja sittemmin tuomioon johtaneita seikkoja. Evansin tuomitsemisen ja teloittamisen jälkeen saatiin selville, että kaksoismurhaan olikin Evansin sijaan syyllistynyt hänen entinen naapurinsa John Christie, jolla oli jo entuudestaan ollut rikostaustaa.

Svartvikin tekemä analyysi merkitsi soveltavan kielentutkimuksen uuden osaalueen, forensisen lingvistiikan, syntyä. Alun hitaasta kehityksestä huolimatta forensisen lingvistiikan voidaan sanoa vakiinnuttaneen asemansa englanninkie- 
lisissä maissa. Merkittävää kasvua alalla on ollut havaittavissa 1990-luvulta lähtien, mistä kielii paitsi korkealaatuisen tutkimuskirjallisuuden, alan oppikirjojen ja yliopistojen tutkintotarjonnan lisääntyminen ${ }^{3}$ myös se tosiseikka, että forensiseen lingvistiikkaan erikoistuneiden asiantuntijoiden hyödyntäminen kielellisten todistusaineistojen analysoinnissa ja todistajina oikeudenkäynneissä on yleistynyt eri maissa.

Nykyisin nimitys forensinen lingvistiikka voidaan hahmottaa yläkäsitteenä monenlaiselle oikeuden kielellisyyttä ja kielellisiä oikeusturvariskejä koskevalle tutkimukselle (ks. esim. Tiersma 2009). Alkuperäisistä lähtökohdistaan tutkimussuuntaus on laajentunut kattamaan monia muita kielitieteen näkökulmasta mielenkiintoisia osa-alueita, kuten plagiarismin tutkimuksen. Yksi viime vuosien tapahtumien valossa mielenkiintoisimmista aihepiireistä on kielianalyysin hyödyntäminen turvapaikanhakijoiden henkilöllisyyden ja kotipaikan selvittämiseksi selvittämiseksi (Language Analysis for Determination of Origin, LADO), mikä edellyttää analyysin tekijältä muun muassa kyseessä olevalla kielialueella käytössä olevien erilaisten murteiden vankkaa tuntemusta (ks. esim. Korkeimman hallinto-oikeuden vuosikirjapäätös KHO 2016:116).

Erityisesti globalisaation, rajat ylittävän rikollisuuden ja kansainvälisen oikeudellisen yhteistyön lisääntymisen myötä kielelliset haasteet oikeusviranomaisten työssä ja oikeudellisissa prosesseissa ovat lisääntyneet. Oli kyse sitten kielellisen todistusaineiston analysoinnista tai monikielisyydestä oikeudellisissa menettelyissä, forensinen lingvistiikka on muodostunut käytännön merkitykseltään tärkeäksi tutkimusalueeksi. Ala herättää yhä

3. Forensisen lingvistiikan tutkinnon voi suorittaa mm. seuraavissa yliopistoissa: Aston University, Cardiff University, Hofstra University, University of York ja Vrije Universiteit Amsterdam. enemmän kiinnostusta, mikä on heijastunut myös IAFL:n jäsenmäärään: tällä hetkellä yhdistyksessä on noin 170 jäsentä yhteensä 26:sta eri maasta.

\section{IAFL 25 vuotta: välitilinpäätös ja katsaus tulevaan}

Tänä vuonna kyseessä oli yhdistyksen 25-vuotisen taipaleen juhlavuosi, ja konferenssin teemaksi oli valittu osuvasti "Forensisen lingvistiikan uudet haasteet" (New challenges for forensic linguistics). Osallistujia konferenssiin oli saapunut toista sataa eri puolilta maailmaa, ja kielitieteilijöiden lisäksi mukana oli oikeusviranomaisten edustajia. Konferenssin teema näkyi ennen kaikkea forensisen lingvistiikan uranuurtajan ja IAFL:n perustajan Malcolm Coulthardin (Aston University / Universidade Federal de Santa Catarina) tervetuliaispuheenvuorossa, jossa hän kävi läpi alan kehitystä 25 viime vuoden aikana ja loi myös katsauksen tulevaan. Vaikka alalla voidaan katsoa tapahtuneen viime vuosikymmeninä paljon kehitystä, Coulthard näki kehittämistarvetta etenkin siinä, että forensinen lingvistiikka tulisi tunnetuksi maantieteellisesti entistä laajemmin ja että tiettyjen, lähes kaikkia oikeusjärjestelmiä koskevien kielellisten haasteiden tutkimuksessa päästäisiin eteenpäin. Näihin haasteisiin lukeutuvat hänen mukaansa erityisesti kielellisen todistusaineiston (esim. sähköinen materiaali) säilyttäminen ja säilymisen turvaaminen oikeusviranomaisissa, oikeuksien ilmoittaminen ymmärrettävästi kiinniotetuille ja kuulusteltaville henkilöille, lasten ja muiden haavoittuvassa asemassa olevien henkilöiden kuulusteluissa hyödynnettävät kuulustelutekniikat sekä tällaisten henkilöiden toimiminen todistajina oikeudenkäynneissä.

Edellä mainittuja tutkimusaiheita käsitteleviä ja niitä sivuavia esitelmiä sisältyikin viisipäiväisen konferenssin moni- 
puoliseen ja intensiiviseen ohjelmaan. Forensisen lingvistiikan kärkinimiin lukeutuvien pääpuhujien Martin Potthastin (Bauhaus-Universität Weimar), Tim Grantin (Aston University), Malcolm Couthardin (Aston University / Universidade Federal de Santa Catarina), Janet Ainsworthin (Seattle University), Alan Durantin (Middlesex University), Shonna Trinchin (City University of New York), Georgina Heydonin (RMIT University) ja Peter Frenchin (University of York) plenaariesitysten ohessa osallistujille oli tarjolla yhteensä 124 konferenssiesitelmää ja 16 posteria neljässä rinnakkaissektiossa. Kaksikielisenä järjestetyn konferenssin englannin- ja portugalinkielisten esitelmien aiheiden kirjo ulottui plagiarismista, forensisesta tekstianalyysista, murteiden tunnistamisesta, vihapuheesta ja korpuslingvististen lähestymistapojen haasteista siviili-, rikos- ja hallintoprosessin $(\mathrm{mm}$. tavaramerkkiriitojen, poliisikuulustelujen, turvapaikanhakijoiden kuulustelujen ja tuomioistuinkäsittelyn) kielen ja laajemmin näiden vuorovaikutustilanteiden tutkimukseen. Oikeustulkkauksen aihepiiristä pidettiin yhteensä yhdeksän esitelmää, mutta sen sijaan oikeudellinen kääntäminen ja forensisen lingvistiikan didaktiikka jäivät konferenssissa taka-alalle. Viikon parasta antia olivat forensista lingvistiikkaa Euroopan ulkopuolisissa maissa käsitelleet esitelmät: muun muassa monikielisiä oikeudenkäyntejä Kiinassa tarkastelleet Lei Yun (Guangdong University of Foreign Studies) ja Eva Ng'n (University of Hong Kong) esitelmät, Susan BerkSeligsonin ja Mitchell Seligsonin (Vanderbilt University) puheenvuoro lynkkausta koskevista narratiiveista Guatemalassa ja Tharwat El-Sakranin (American University of Sharjah) esitelmä Yhdistyneiden arabiemiirikuntien asianajajilla teetetystä forensista lingvistiikkaa koskevasta kyselytutkimuksesta ja sen tuloksista.

Kaikessa monimuotoisuudessaan esitelmät antoivat osallistujille konferens- sin teeman mukaisesti hyvän kuvan siitä, minkälaisten haasteiden edessä forensinen lingvistiikka tieteenalana tänä päivänä on ja minkälaisia sudenkuoppia forensiset lingvistit työssään soveltavan kielentutkimuksen ammattilaisina saattavat kohdata. Keskusteluun nostettiin alan uusien tuulien ja kehittyvän teknologian mukanaan tuomien mahdollisuuksien lisäksi myös joitakin perustavanlaatuisia näkökohtia, jotka ovat mietityttäneet monia alan tutkijoita jo pitkään. Näihin lukeutuivat muun muassa kysymykset siitä, tulisiko alan nimitys ottaa uudelleen yhteisesti pohdittavaksi ja millä tavoin forensinen lingvistiikka ja suomalaisittain tunnetumpi oikeuslingvistiikka (legal linguistics, Rechtslinguistik) tai oikeus ja kieli -suuntaus (language and law, Recht und Sprache) eroavat toisistaan (ks. Mattila 2002). Vilkasta keskustelua sai aikaan näiden nimitysten välinen rajanveto, jota hankaloittaa alojen tutkimuskohteiden ja tutkimusmenetelmien osittainen päällekkäisyys.

\section{Forensiset lingvistit soveltavan kielentutkimuksen asiantuntijoina}

Yksityiskohtaisimmin forensisen lingvistin ammattiin ja asiantuntemukseen pureuduttiin IAFL:n väistyvän puheenjohtajan Tim Grantin plenaariesityksessä, jossa käsiteltiin forensisen kielianalyysin hyödyntämistä oikeudellisessa tutkinnassa ja todistelussa. Grant aloitti puheenvuoronsa määrittelemällä forensisen lingvistiikan yleisesti pyrkimykseksi edistää oikeuden toteutumista kielitieteellisen analyysin keinoin. Tähän tavoitteeseen tähtäävät kaikki kolme hänen hahmottamaansa osa-aluetta:

1) oikeudellisten tekstien ja kontekstien kielitieteellinen tutkimus,

2) oikeudellisten prosessien kielitieteellinen tutkimus ja

3) oikeudelliseen prosessiin liittyvän asian tutkintaa tukeva kielitieteellinen tutkimus. 
Painopisteenä Grantin esitelmässä oli edellä mainittu kolmas osa-alue, jonka hän määritteli forensisesta näkökulmasta mielenkiintoisten tekstien tutkimiseksi oikeudellisen asian tutkinnan ja/tai todistelun edistämistarkoituksessa. Forensisen lingvistin toimenkuvaan voi tällaisessa tapauksessa kuulua yllättävän laaja kirjo työskentelyalueita, kuten poliisiviranomaisten avustamista tietyn esitutkintaan liittyvän tekstin kirjoittajan profiloimiseksi tai tunnistamiseksi (esim. uhka- tai kiristyskirjeet) tai asiantuntijatodistajana toimimista siviili-, hallintotai rikosasioissa. Kielelliset seikat saattavat olla jutun ratkaisemisen ja oikeuden toteutumisen kannalta olennaisia mitä erilaisimmissa oikeudellisissa asioissa, joten toimenkuva saattaa pitää sisällään perehtymisen vaikkapa tavaramerkkioikeuteen (esim. Butters 2010; Shuy 2002) tai slangisanojen merkityssisältöihin (esim. Grant 2017).

Kielellisen todistusaineiston ja forensisen lingvistin laatiman asiantuntijalausunnon käyttäminen tuomioistuimessa oikeudellisen päätöksenteon perustana on edelleen asia, johon kytkeytyy monia epäselvyyksiä ja riskejä. Näitä on pohtinut fokusoidummin Grantin esityksessään esiin tuoma tieteellisiin asiantuntijalausuntoihin erikoistunut oikeustieteen professori Edward K. Cheng, joka on herättänyt artikkelissaan "Being pragmatic about forensic linguistics" (2013) tärkeitä kysymyksiä alan asiantuntijuudesta ja asiantuntijatodistelun luotettavuuden arvioimisesta: Kenellä on riittävä pätevyys ja taito toimia forensisen lingvistiikan asiantuntijana, tehdä kielitieteellisiä analyyseja ja laatia lausuntoja oikeusviranomaisten käyttöön? Mistä oikeusviranomainen voi tunnistaa, liioitteleeko kyseinen henkilö osaamistaan ja kykyjään? Osaako asiantuntija antaa ymmärrettävän selvityksen käyttämästään analyysimenetelmästä? Pystyykö hän tunnistamaan mahdolliset menetelmälliset virheet analyysissaan ja puuttumaan niihin asianmukaisella tavalla?

Kielellisiä todisteita analysoivalla ja tuomioistuimessa todistajana esiintyvällä forensisen lingvistiikan asiantuntijalla on oikeuskääntäjän ja oikeustulkin tavoin merkittävä rooli oikeusjärjestelmässä oikeuden toteutumisen kannalta. Onkin helppo yhtyä Grantin esittämään vaatimukseen siitä, että kielitieteellisessä analyysissa käytettyjen menetelmien tulee olla läpinäkyviä. Tämä on ensiarvoisen tärkeää oikeudenmukaisen oikeudenkäynnin ja oikeusturvan toteutumisen turvaamiseksi. Menetelmien merkitys tutkimustulosten validiteetin takaajina korostuu, sillä forensisessa lingvistiikassa analyysimenetelmä valitaan usein tapauskohtaisesti tarkasteltavan aineiston perusteella (Cheng 2013: 542). Virheellinen analyysimenetelmä saattaa johtaa virheellisiin päätelmiin ja siten virheellisen tai puutteellisen arvion sisältävään asiantuntijalausuntoon. Hyvänä lähtökohtana voidaan Grantin mukaan pitää sitä, että forensisten lingvistien laatimien kielitieteellisten lausuntojen tulee olla kokonaisuudessaan riittävän läpinäkyviä perustellun päätöksenteon mahdollistamiseksi (vrt. mas. 547).

\section{Jatkotutkimukselle tarvetta myös Suomessa}

Konferenssi valotti forensisen lingvistiikan monipuolista tutkimuskenttää uusien haasteiden ja näitä koskevien mahdollisten ratkaisujen näkökulmasta sekä antoi alan tutkijan silmin runsaasti kimmokkeita jatkotutkimukseen. Suomen oikeusjärjestelmä ei ollut tällä kertaa edustettuna konferenssiesitelmissä, mikä ei sinänsä ollut yllättävää. Suomessa forensisen lingvistiikan voidaan sanoa olevan vielä lapsen kengissä; esimerkiksi alan kirjallisuuden osalta tällä hetkellä olemassa oleva suomenkielinen materiaali rajoittuu muutamaan artikkeliin (Salmi-Tolonen 2008; 
Tiililä 2014) ja yhteen opinnäytetyöhön (Rentola 2017). Vastaavasti opetuksen saralla forensisesta lingvistiikasta on Suomessa järjestetty vasta yksi yliopistotason luentosarja, joka pidettiin syksyllä 2015 Lapin yliopiston oikeustieteiden tiedekunnassa oikeuslingvistiikan oppiaineen opetustarjonnan puitteissa. Kuten konferenssin rikkaasta esitelmätarjonnasta kävi selvästi ilmi, ei forensinen lingvistiikka nimityksestään huolimatta rajoitu yksinomaan kielitieteen soveltamiseen rikosasioihin ja rikosprosessiin, vaikka kielelliset rikokset, kuten Suomen rikoslaissa (RL) kunnianloukkaus (RL 24:9), kiihottaminen kansanryhmää vastaan (RL 11:10) ja laiton uhkaus (RL 25:7), ovatkin kaikkein ilmeisimpiä forensisen lingvistiikan soveltamisalueita. Kielentutkijan asiantuntemusta voidaan kaivata erityyppisissä oikeudellisissa asioissa ja yhteyksissä. Alan edistämiseksi Suomessa tarvitaankin yhtäältä lisää järjestelmällistä empiiristä tutkimusta vastaamaan käytännön tiedontarpeisiin ja toisaalta tutkimukseen perustuvaa laadukasta opetusta ja koulutusta yleisen tietoisuuden lisäämiseksi forensisesta lingvistiikasta ja sen mahdollisuuksista.

EMILIA LINDROOS etunimi.sukunimi@ulapland.fi

\section{Lähteet}

Butters, Ronald 2010: Trademarks. Language that one owns. - Malcolm Coulthard \& Alison Johnson (toim.), The Routledge handbook of forensic linguistics s. 351-364. Abingdon: Routledge.

Cheng, Edward K. 2013: Being pragmatic about forensic linguistics. - Journal of
Law \& Policy 21 s. 541-550.

Grant, Tim 2017: Duppying yoots in a dog eat dog world, kmt. Determining the senses of slang terms for the Courts. Semiotica 2017 (216) s. 479-495.

The International Journal of Speech, Language and the Law. https://journals.equinoxpub.com/index.php/IJSLL.

Language and Law. Linguagem e Direito. http://llld.linguisticaforense.pt/.

Korkeimman hallinto-oikeuden vuosikirjapäätös 17.8.2016. KHO 2016:116.

Mattila, Heikкi E. S. 2002: Vertaileva oikeuslingvistiikka. Helsinki: Talentum.

Rentola, Roosa 2017: Forensinen lingvistiikka. Kielentutkimuksen hyödyntäminen esitutkinnassa ja tuomioistuimessa. Poliisiammattikorkeakoulun opinnäytetyö.

$\mathrm{RL}=$ Rikoslaki (19.12.1889/39).

SAlmi-Tolonen, TARJA 2008: Forensista lingvistiikkaa - kielentutkimuksen juridisia sovelluksia. - Richard Foley, Tarja Salmi-Tolonen, Iris Tukiainen \& Birgitta Vehmas (toim.), Kielen ja oikeuden kohtaamisia s. 375-393. Helsinki: Talentum.

Shuy, Roger 2002: Linguistic battles in trademark disputes. Basingstoke: Palgrave Macmillan.

Svartvik, JAn 1968: The Evans statements. A case for forensic linguistics. Göteborg: University of Göteborg.

TiIlilä, Ulla 2014: Verbaaliset sormenjäljet. Kielentutkimus huijausten ja rikosten tutkinnassa. - Kielikello 4/2014 s. 14-17.

Tiersma, Peter 2009: What is language and law? And does anyone care? - Frances Olsen, Alexander Lorz \& Dieter Stein (toim.), Law and language. Theory and society. Loyola-LA Legal Studies Paper No. 2009-11 s. 9-37. Düsseldorf: Düsseldorf University Press. 